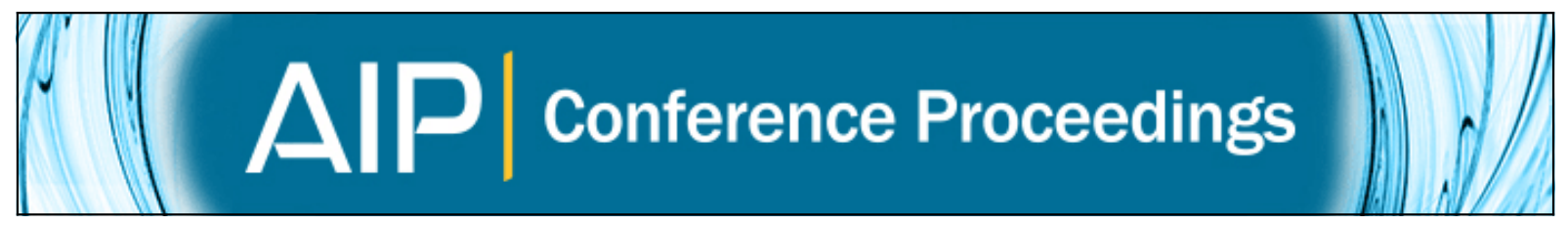

\title{
Estimation of foot pressure from human footprint depths using 3D scanner
}

Dwi Basuki Wibowo, Gunawan Dwi Haryadi, and Agus Priambodo

Citation: AIP Conference Proceedings 1717, 040008 (2016); doi: 10.1063/1.4943451

View online: http://dx.doi.org/10.1063/1.4943451

View Table of Contents: http://scitation.aip.org/content/aip/proceeding/aipcp/1717?ver=pdfcov

Published by the AIP Publishing

\section{Articles you may be interested in}

The feasibility of a scanner-independent technique to estimate organ dose from MDCT scans: Using CTDI vol to account for differences between scanners

Med. Phys. 37, 1816 (2010); 10.1118/1.3368596

Stereomammography: Evaluation of depth perception using a virtual 3D cursor

Med. Phys. 27, 1305 (2000); 10.1118/1.599008

Math Is Key to Identifying Source of 'Strange Foot-Print'

Phys. Today 50, 15 (1997); 10.1063/1.881905

Paul D. Foote

Phys. Today 24, 73 (1971); 10.1063/1.3022449

Humanity's water footprint

Phys. Today 


\title{
Estimation of Foot Pressure from Human Footprint Depths Using 3D Scanner
}

\author{
Dwi Basuki Wibowo $^{1, a)}$ Gunawan Dwi Haryadi ${ }^{1, b)}$ Agus Priambodo $^{2, c)}$ \\ ${ }^{1}$ Mechanical Engineering Dept., Faculty of Engineering, Diponegoro University, Indonesia \\ ${ }^{2}$ Orthopedic Dept., Faculty of Medicine, Diponegoro University, Indonesia \\ ${ }^{a)}$ Corresponding author: rmt.bowo@gmail.com \\ b)gunawan_dh@engineer.com \\ c)priambodo_aguspr@yahoo.co.id
}

\begin{abstract}
The analysis of normal and pathological variation in human foot morphology is central to several biomedical disciplines, including orthopedics, orthotic design, sports sciences, and physical anthropology, and it is also important for efficient footwear design. A classic and frequently used approach to study foot morphology is analysis of the footprint shape and footprint depth. Footprints are relatively easy to produce and to measure, and they can be preserved naturally in different soils. In this study, we need to correlate footprint depth with corresponding foot pressure of individual using 3D scanner. Several approaches are used for modeling and estimating footprint depths and foot pressures. The deepest footprint point is calculated from $\mathrm{z}$ max coordinate- $\mathrm{z}$ min coordinate and the average of foot pressure is calculated from GRF divided to foot area contact and identical with the average of footprint depth. Evaluation of footprint depth was found from importing 3D scanner file (dxf) in AutoCAD, the z-coordinates than sorted from the highest to the lowest value using Microsoft Excel to make footprinting depth in difference color. This research is only qualitatif study because doesn't use foot pressure device as comparator, and resulting the maximum pressure on calceneus is $3.02 \mathrm{~N} / \mathrm{cm}^{2}$, lateral arch is $3.66 \mathrm{~N} / \mathrm{cm}^{2}$, and metatarsal and hallux is $3.68 \mathrm{~N} / \mathrm{cm}^{2}$.
\end{abstract}

\section{INTRODUCTION}

During human on locomotion in foot plantar turn up pressure as reaction from supporting surface. The study which learn about distribution foot pressure is pedobarography used most often for biomechanical analysis of gait and posture and clinical application. The most widely researched clinical application is diabetic foot ulceration [1], a condition which can lead to amputation in extreme cases [2] but for which even mild-to-moderate cases are associated with substantial health care expenditure [3]. Pedobarography is also used in a variety of other clinical situations including: post-surgery biomechanical assessment [4], intra-operative assessment [5], orthotics design [6, 7], and assessment of drop-foot surgery [8]. In addition to clinical applications, pedobarography continues to be used in the laboratory to understand the mechanisms governing human gait and posture $[9,10]$. Study of human foot plantar pressure also can be used for obesity estimated [11], foot pain [12], normal foot and disability [13], and orthotic shoes insole design $[14,15,16]$.

Foot pressure measurement systems provide unique insight on foot function and gait, helping clinicians conduct more complete assessments and objectively evaluate treatments. In the clinical setting, these system are used by podiatrists, orthotists, prosthestists, and physical therapists around the world. For produce distribution foot/plantar pressure for clinical and research needed accurate and precision measuring devices. Some of devices on the market using different technology such as resistive, elastomer-based capacitive, and air-based capacitive [17] that commonly with expensive price. Because of that, some of researcher estimate that from footprint depth/shape [18, $19,20]$ with lower cost.

A number of studies have taken different approaches to inferaspects of human gait from footprint shape. Some have compared experimentally produced human footprints with fossil hominin footprints or differences in gait [21, 
22]. Others have used records of plantar pressure distribution in human and non-human primates as hypothetical footprint shapes, and compared those with the morphologies of fossil hominin footprints [23].

Measuring footprint depth for estimate GRF (Ground Reaction Force) was done by Balbinot et al. with using wood rack fillet with clay as media for footprint [20]. Force measurements were performed using a force platform, at the same time a footprint was registered on a clay surface. From the measurements of length, width, and depth of the footprint it was possible to estimate body height (BH), body mass (BM), and vertical GRF peaks during human walking. Next Kevin G. Hatala et al. [24] and A.K. Chong et al [25] research relation betweeen footprint shape with plantar pressure. Kevin G. Hatala using RSscan International Footscan Pressure (RSscan International, Olen Belgium) for measuring foot pressure and the sediment excavated directly from a fossil layer containing hominin footprints from Ileret Kenya as media for measuring footprint depth. While A.K. Chong using two types of system which are suitable for capture of pressure and they are commonly known as floor mat or floor pad and in-shoe pad. For the floor mat system pressure values are displayed as image roomates does not depict the foot shape. Therefore, shortcoming of this system for recording plantar pressure during walking is that the location of the pressure value related to the plantar surface is only approximate. Kulkarni et al [26] also investigated the correlation footprint corresponding image with a Body Mass Index (BMI) of individuals using image processing principles, i.e. pedobarographic images consist of Red, Green and Blue colors. In this method each color pixel count correlates with the pressure points of the human foot and with a relatively BMI.

In this paper, we present an experimental approach for understanding how the distribution of plantar pressure is recorded in footprint depth produced by $3 \mathrm{D}$ scanner. So, we need to correlate footprint images with corresponding foot pressure of individual using image processing principles. Footprint depth obtained from the variation zdirection results scanner while the contact area of the foot is obtained from printing foot on paper charts. This study only produce an image of foot pressure distribution is qualitatively in the heel, lateral arch and metatarsal area because no pressure measurements were taken using foot pressure measurement devices.

\section{METHODOLOGY 3D Scanning Methodology}

A 3D scanner is a device that analyses a real-world object or environment to collect data on its shape and possibly its appearance (e.g. color). The collected data can then be used to construct digital three-dimensional model which is useful for a wide variety of applications. These devices are used extensively by the entertainment industry in the production of movies and video games. Other common applications of this technology include industrial design, orthotics and prosthetics, reverse engineering and prototyping, quality control/inspection and documentation of cultural artifacts.

In this paper, we use 3D Scanner Mini and Scansoft for Foot Orthotic made by Vismach Technology Ltd. China [27]. These scanner are active stereo vision 3D tech with white light pattern projection or no laser, thus it is safe on the eye, quick capture $(0.1-0.2 \mathrm{sec})$, clean 3D mesh, and $\pm 1.0 \mathrm{~mm}$ linier accuracy. The output 3D model of foot is in the standard language $(\mathrm{dxf} / \mathrm{st} / \mathrm{wrl} / \mathrm{obj} / \mathrm{ply} / \mathrm{asc})$ format that can be exported into AutoCAD and fabricated by the (stl) images to the rapid prototyping machine.

To obtain a 3D foot image is scanning soles of the feet as seen in Fig. 1. The output can be in the form of 3D plantar of foot (Fig. 2) and 3D models and 3D foam positive impressions (Fig. 3). To see the all footprint coordinates, the 3D scanner output file must be exported to AutoCAD software.

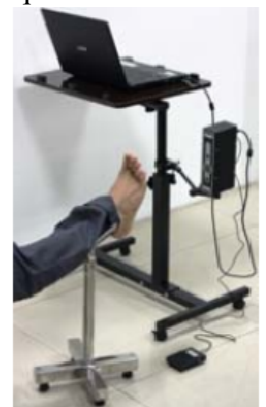

FIGURE 1. Scanning of the foot 


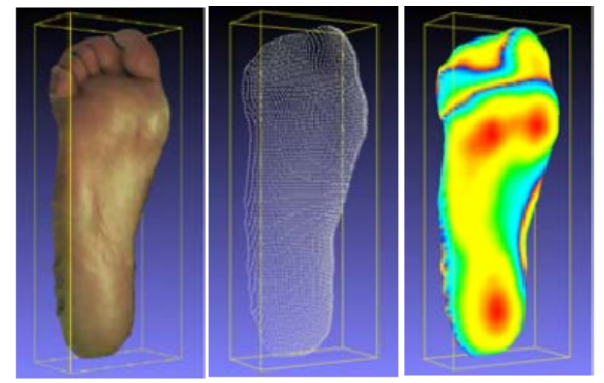

FIGURE 2. 3D plantar only output
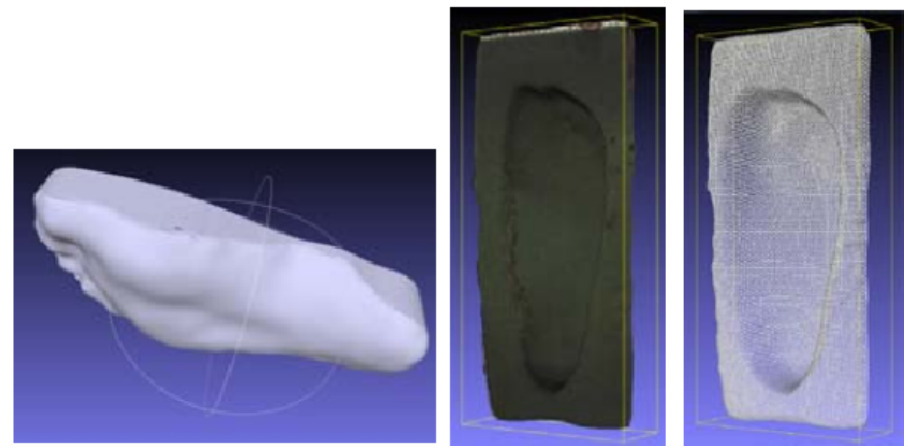

FIGURE 3. 3D positive model and foam impression result

\section{Traditional Foot Printing}

Until now in all hospitals and Health Polytechnics in Indonesia are still using the traditional foot printing to determine abnormalities in the foot (flat foot and high arch), foot length (FL), foot width (FW), and the area of contact. FL and FW data to predict body height (BH) and body mass (BM) respectively [20]. While the contact area is used to estimate average contact pressure on the soles of the feet. Orthotic shoe insole design is still based on the results of this printing traditional foot.

Figure 4 shows the results of printing on paper charts foot dimension of each rectangular roomates is $1 \mathrm{x} 1 \mathrm{~cm}$. Footprint like this can only be produced by plantar pressure measurement platform devices [17] or plantar image platform [27], cannot use a 3D scanner apparatus. In this paper we use this printing traditional foot to correct the data export to AutoCAD 3D scanning results.

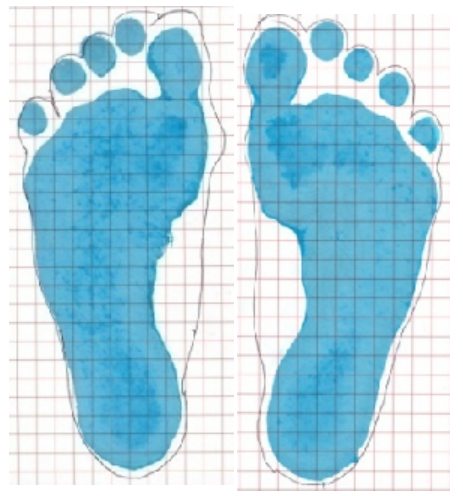

FIGURE 4. The result of traditional foot printing 


\section{Modeling with AutoCAD}

In this paper we used AutoCAD to evaluate footprint depth (z-coordinate values). The coordinates imported from 3D scanner to AutoCAD was then rendered into a solid model, as shown in Fig. 5. By the combination of the traditional foot printing and the AutoCAD file we can subtract the unwanted edges and surface from the AutoCAD solid model. This method known as a Boolean operation which those facility available on AutoCAD [28], but because the traditional printing is not a digital format equalization shapes done manually. Figure 6 shows lateral foot plantar from AutoCAD before and after trimmed.
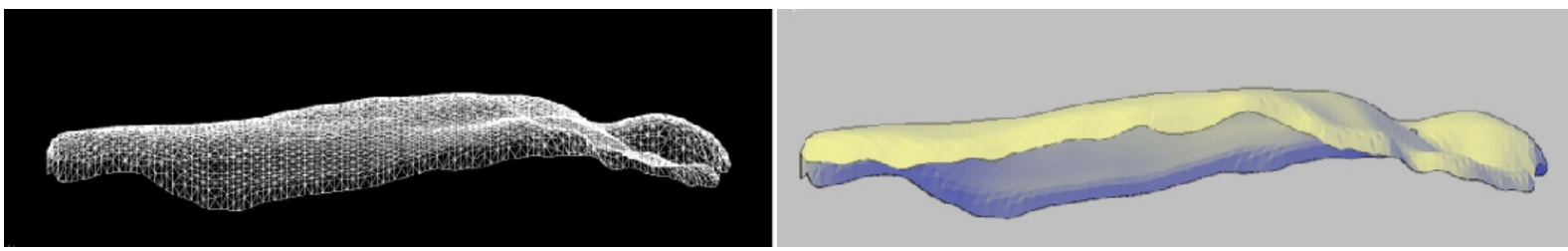

FIGURE 5. 3D longitudinal view of the plantar foot in AutoCAD before and after rendered

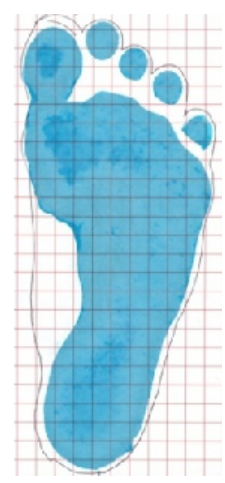

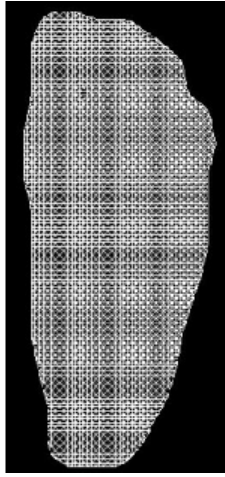

(a). before

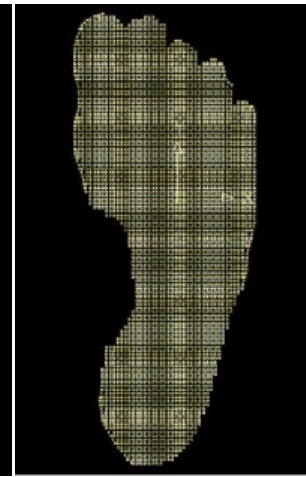

(b). after

FIGURE 6. Foot plantar before and after trimming

To find the footprint depth entire the 3D model surface after trimmed, the z-coordinates value than sorted from the highest value to the lowest value using Microsoft Excel. Furthermore, by choosing the color in AutoCAD is a highest red and dark blue is a lowest $\mathrm{z}$ value and plot the plantar of foot, we can see the distribution of foot printing depth in color difference.

\section{Estimation of Foot Pressure Average}

In this paper foot pressure average was found from GRF divided by the foot area contact, while GRF is equal to body weight (BW, equal BM cross gravitational acceleration $\mathrm{g}$ ) subjects. From footprint measurements it was also possible to estimate subject's BH and BM applying Krishan equation [20,28] using as input data FW, as the following.

$$
\begin{aligned}
& B H=5.414 \times F W+120.951 \\
& B M=2.86 \times F W+37.63
\end{aligned}
$$

where $\mathrm{BH}$ and $\mathrm{FW}$ in $\mathrm{cm}$ and $\mathrm{BM}$ in $\mathrm{kg}$.

This study is characterized as a cross-sectional quantitative comparison. The sample was composed of six individuals (four men and two women) with average $\mathrm{BH}$ and $\mathrm{BM}$ of $163 \mathrm{~cm}$ and $58 \mathrm{~kg}$ respectively. Volunteers were healthy, without notable asymmetries on lower limbs alignment and without history of orthopedic trauma. The 
experiments were carried out at the Laboratory for Biomechatronics of the Mechanical Engineering Department Diponegoro University Semarang (Indonesia).

\section{RESULTS AND DISCUSSION}

There are simple technique for finding coordinates of the AutoCAD 3D model. First, import dxf file from the 3D scanner in AutoCAD. After converted this file to solid model and there are no mistakes compared to 3D scanner, next open Microsoft Excel and then import this AutoCAD coordinates. Back to the AutoCAD software and block the object which want to knowed the coordinate, automatically the coordinate data will appear on new sheet in Microsoft Excel.

From the footprint depth entire the 3D model surface showed that the deepest footprint point at the heel area (called calcaneus depth) is $2.245 \mathrm{~cm}$, lateral arch area (called lateral arch depth) is $2.723 \mathrm{~cm}$, and metatarsal and hallux area (called metatarsal depth) is $2.733 \mathrm{~cm}$. These deepest point are found from equation:

$$
\begin{array}{ll}
\text { Calcaneus depth } & =(\mathrm{z} \text { max coordinate }) \text { calcanea }-(\mathrm{z} \text { min coordinate }) \text { all area } \\
\text { Lateral arch depth } & =(\mathrm{z} \text { max coordinate }) \text { lateral arch }-(\mathrm{z} \text { min coordinate }) \text { all area } \\
\text { Metatarsal depth } & =(\mathrm{z} \text { max coordinate }) \text { metatarsal } \& \text { hallux }-(\mathrm{z} \text { min coordinate }) \text { all area }
\end{array}
$$

Figure 7. shows the footprint depth in difference color image, red is a highest and dark blue is a lowest $\mathrm{z}$ value.

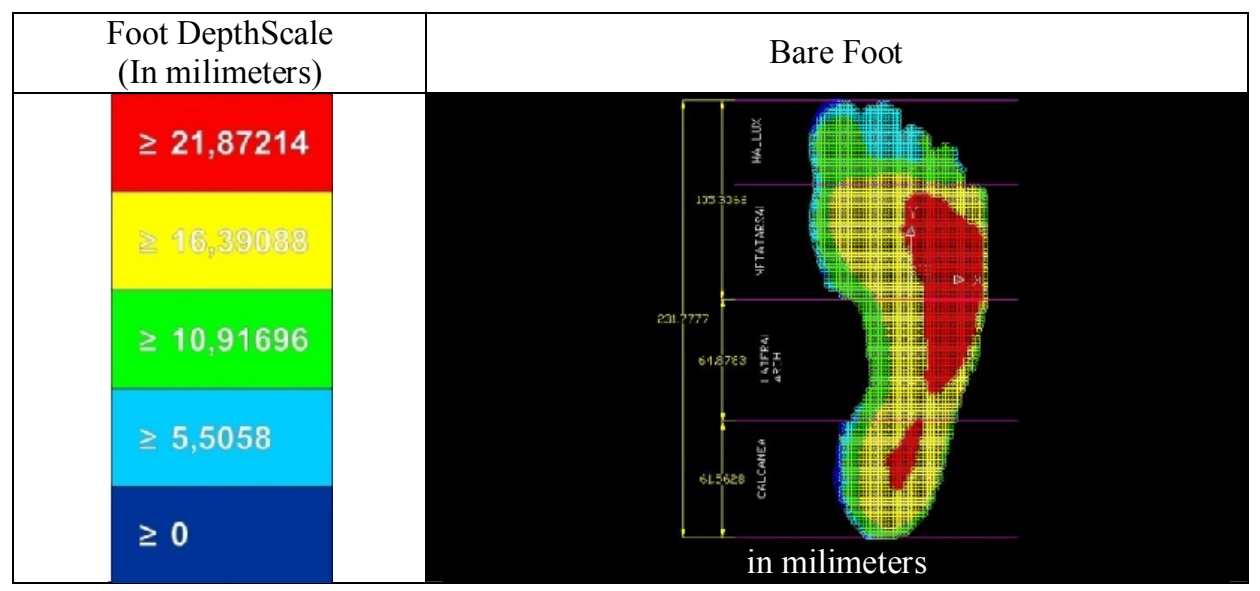

FIGURE 7. Footprint depth one of subject research (S6) in image color

In this paper the amount of GRF is estimated from the BM of the subject's obtained from mathematical equation with purpose based on ussually using method from hominin footprint contur only. Table 1 shows the outcomes for $\mathrm{BH}$ and $\mathrm{BM}$ using stadiometer and force plate, and estimated values obtained by equation 1 and 2 for 6 subjects. From the linier regression equation we can get the standard deviation (SD) of BM both from measurment and calculation by equation 2 . The average of foot pressure then can be estimated from the $50 \% \mathrm{BW}$ divided by the foot area, as shown in Table 2.

TABLE 1. Measurements of BH and BM and estimated by mathematical equation

\begin{tabular}{|c|c|c|c|c|c|c|}
\hline Subject & \multirow{2}{*}{$\begin{array}{c}\text { FL } \\
\end{array}$} & \multirow{2}{*}{$\begin{array}{c}\text { FW } \\
(\mathrm{cm})\end{array}$} & \multicolumn{2}{|c|}{ BH $(\mathrm{m})$} & \multicolumn{2}{c|}{ BM $(\mathrm{kg})$} \\
\cline { 5 - 7 } & 26.4 & 10.3 & Equation 1 & Measurement & Equation 2 & Measurement \\
\hline S1 (men) & 26.7 & 10.2 & 1.76 & 1.70 & 67.088 & 73.1 \\
\hline S2 (men) & 23.8 & 9.9 & 1.74 & 1.66 & 66.802 & 58.3 \\
\hline S3 (men) & 23.8 & 1.60 & 69.944 & 70.3 \\
\hline S4 (woman) & 23.7 & 8.5 & 1.66 & 1.55 & 61.94 & 40.9 \\
\hline S5 (woman) & 24.5 & 9.1 & 1.70 & 1.63 & 63.656 & 55.6 \\
\hline S6 (men) & 25.3 & 10.5 & 1.77 & 1.64 & 67.66 & 49.8 \\
\hline
\end{tabular}


TABLE 2. Estimation average foot pressure based on BM measurements and by mathematical equation

\begin{tabular}{|c|c|c|c|}
\hline Subject & \multirow{2}{*}{$\begin{array}{c}\text { Foot Area } \\
\left(\mathrm{cm}^{2}\right)\end{array}$} & \multicolumn{2}{|c|}{$\begin{array}{c}\text { Average foot pressure estimated from BM } \\
\text { by }\left(\mathrm{N} / \mathrm{cm}^{2}\right)\end{array}$} \\
\cline { 3 - 4 } & & Equation 2 & Measurement \\
\hline S1 (men) & 135 & 2.437 & 2.656 \\
\hline S2 (men) & 139 & 2.357 & 2.057 \\
\hline S3 (men) & 136 & 2.523 & 2.535 \\
\hline S4 (woman) & 124 & 2.450 & 1.612 \\
\hline S5 (woman) & 127 & 2.459 & 2.147 \\
\hline S6 (men) & 138 & 2.405 & 1.770 \\
\hline Mean & & 2.439 & 2.130 \\
\hline
\end{tabular}

By assuming the average of foot pressure is identical with the average of footprint depth $1.813 \mathrm{~cm}$, for individual subject S6 we found the maximum pressure on calceneus is $3.02 \mathrm{~N} / \mathrm{cm}^{2}$, lateral arch is $3.66 \mathrm{~N} / \mathrm{cm}^{2}$, and metatarsal and hallux is $3.68 \mathrm{~N} / \mathrm{cm}^{2}$.

The present study illustrates the successful application of 3D scanner method to the quantitative interpretation of the footprint. Three aspects have to be taken into account accurately: (1) the footprint coordinates result which get from plantar foot, (2) the area of foot plantar which get from plantar foot print on paper charts, and (3) the relationship between footprint depth and foot pressure. The constitutive solid model from AutoCAD describes footprint depth in a most a realistic manner since it takes into account foot pressure distribution dependent foot position while scanning. The foot plantar position which not perpendicular with foot ankle and hallux which bend to front/back/side will affect the result of footprint depth. The accuration of scanning result will see from the result plotting footprint depth in shape of colored image.

The area of foot plantar offcourse are relatively accurate, as long as the subject when printing stand up-right. But because the traditional printing is not a digital format, the combination with AutoCAD plantar foot model can not be done by Boolean operation. This will affect the accuracy of the calculation of the average footprint depth.

The calculation of average foot pressure from GRF divided to foot contact area, where GRF is equal to BW, logically quite accurate. But to equate the average foot pressure to the average depth of the footprint is rather confuse. The accuracy of the results will be seen from the human pressure foot values that have been conducted by researchers before.

This study indicates that the average of footprint depth is $1.813 \mathrm{~cm}$ and the average of foot pressure is 2.439 $\mathrm{N} / \mathrm{cm}^{2}$. The deepest footprint point at the heel area is $2.245 \mathrm{~cm}$ (equivalent to $3.02 \mathrm{~N} / \mathrm{cm}^{2}$ ), lateral arch area is 2.723 $\mathrm{cm}$ (equivalent to $3.66 \mathrm{~N} / \mathrm{cm}^{2}$ ), and metatarsal and hallux area is $2.733 \mathrm{~cm}$ (equivalent to $3.68 \mathrm{~N} / \mathrm{cm}^{2}$ ). This result is different at about $30 \%$ from Eleftherios Kellis research which result peak and mean pressure during standing on 2 feet $(\mathrm{SO} 2 \mathrm{~F})$ i.e. $50 \mathrm{kPa}$ and $35 \mathrm{kPa}$ respectively [30].

\section{CONCLUSION}

Our work represents a first step in the direction of calculating the human footprint depth using 3D scanners Mini and Scansoft for Foot Orthotic. However, several additional footprint characteristics have to be considered before reliable results can be obtained accurately. These include scanning processes that alter the original contour of the feet such as the (1) identification of the defect on the soles of the feet (i.e. flat foot or high arch), (2) influence the position of the feet that are not true to the distribution footprint depth, and (3) identification of the plantar surface after the footprint was created. Accordingly, in ongoing research the subjects was selected which did not have defects in the sole of the foot even though this is not an any problems. Problems arise precisely when scanning of foot that shows footprint results are not in accordance with the depth should be. To fix the scanning process needs to be repeated and in this depth research footprint in the form of colored image, as seen in Fig. 7, is the best result. Plantar surface models is another issue that affects the calculation of footprint area. Boolean operation can not be done here because the traditional printing is not a digital format. The solution is to produce an accurate image of the plantar foot when subtract the unwanted edges and surfaces from AutoCAD solid models is done carefully, the best results of which are shown in Fig. 7. 
Foot pressure average, which is calculated from the GRF divided to foot contact area, the results are relatively accurate in the amount of $2.405 \mathrm{~N} / \mathrm{cm}^{2}$ for S6 subject's. By equating foot pressure averages with the average depth of the footprint can be obtained maximum value of foot pressure on the heel, lateral arch, and metatarsal area. In this research we found the deepest footprint point at the heel area is $2.245 \mathrm{~cm}$ (equivalent to $3.02 \mathrm{~N} / \mathrm{cm}^{2}$ ), lateral arch area is $2.723 \mathrm{~cm}$ (equivalent to $3.66 \mathrm{~N} / \mathrm{cm}^{2}$ ), and metatarsal and hallux area is $2.733 \mathrm{~cm}$ (equivalent to $3.68 \mathrm{~N} / \mathrm{cm}^{2}$ ).

\section{REFERENCES}

1. Van Schie CHM, Int. J. Low Extrem. Wounds 4, 160-170 (2005).

2. Klenerman L, Wood B., The Human Foot: A Companion to Medical Studies, (Springer, Berlin, 2006).

3. Reiber GE, Diabetes Care 15, 29-31 (1992).

4. Hahn F, Maiwald C, Horstmann T, Vienne P, Clin. Biomech. 23, 109-16 (2008).

5. Richter M, Frink M, Zech S, Geerling J, Droste P, Knobloch K, Krettek C, Tech. Foot Ankle Surg. 5, 88-100 (2006).

6. Hodge MC, Bach TM, Carter GM, Clin. Biomech. 14, 567-75 (1999).

7. E. Eils, S. Nolte, M. Tewes, L. Thorwesten, K. Volker, D. Rosenbaum, J. Biomech. 35, 1307-1313 (2002).

8. B Parmar, "Assessment of Foot Drop Surgery in Leprosy Subjects Using Frequency Domain Analysis of Foot Pressure Distribution Images”, in 13th International Conference on Biomedical Engineering, IFMBE Proceedings, edited by C. T. Lim, et al. (Springer-Verlag Berlin Heidelberg, Berlin, 2009) pp. 1107-1111.

9. I. J. Alexander, E. Y. Chao, K. A. Johnson, Foot Ankle 11, 152-67 (1990).

10. D. Rosenbaum, H. P. Becker, J. Foot Ankle Surg. 3, 1-14 (1997).

11. M. Birtane, H. Tuna, Clin. Biomech. 19, 1055-1059 (2004).

12. N.L.W. Keijsers, N.M. Stolwijk, J.W.K. Louwerens, J. Duysens, Clin. Biomech. 28, 350-356 (2013).

13. R. M. Queen, N. A. Mall, J. A. Nunley, B. Chuckpaiwong, Gait Posture 29, 582-586 (2009).

14. S. E. Praet, J. W. K. Louwerens, Diabetes Care, 26 (2003).

15. D. R. Bonanno, K. B Landorf and H. B. Menz, J. Foot Ankle Res. 4, Suppl. 1 p.6 (2011)

16. T. L. Lin, H. M. Sheen, C. T. Chung, S. W. Yang, S.Y. Lin, H. J. Luo, C.Y. Chen, I. C. Chan, H. S. Shih and W. H. H. Sheu, J. Foot Ankle Res. 6, 1-9 (2013).

17. C. Giacomozzi, Gait Posture 32, 141-144 (2010).

18. A. Abbasi, H. B. Tabrizi, H. J. Sarvestani, K. Bagheri, Annals Biolog. Res. 2(6), 102-108 (2011).

19. G. Gravante, G. Russo, F. Pomara, C. Ridola, Clin. Biomech. 18, 780-782 (2003).

20. G. Balbinot, Int. J. Basic Appl. Sci. 3 (1), 30-34 (2014).

21. M. H. Day, E. H. Wickens, Nature 286, 385-387 (1980).

22. J. Charteris, J. C. Wall, J. W. Nottrodt, Nature 290, 496-498 (1981).

23. R. H. Crompton, T. C. Pataky, R. Savage, K. D'aout, M. R. Bennett, M. H. Day, K. Bates, S. Morse, W. Sellers, J. Royal Soc. Interface 9, 707-719 (2012).

24. K. G. Hatala, H. L. Dingwall, R. E. Wunderlich, B. G. Richmond, J. Hum. Evol. 65, 21-28 (2013).

25. A. K. Chong, J. A. Al-Baghdadi, P. Milburn, J. Biosci. Medicines 3, 36-41 (2015).

26. P. S. Kulkarni, V. B.Kulkarni, Int. J. Adv. Res. Elec Commun. Eng. 3, 1-4 (2014).

27. ScanPod3D, 2013, "3D Scanner Mini and Scansoft for Foot Orthotic", Vismach Technology Ltd., www.scanpod3d.com

28. S. K. Paul, S. Sivarasu, L. Mathew, Engineering 4, 692-695 (2012).

29. K. Krishhan, Forensic Sci. Int. 179, 63-69 (2008).

30. E. Kellis, Gait Posture 14, 92-97 (2001). 